\title{
DETERMINANTS FOR THE UTILIZATION OF ANTENATAL CARE IN NEPAL
}

\section{HARI PRASAD KAPHLE ${ }^{1}$, NEENA GUPTA ${ }^{2}$, NAVEEN SHRESTHA ${ }^{3}$,} ANUPRIYA PAUL ${ }^{4}$, ARVIND DAYAL $^{5} \&$ AKANKSHA SINGH ${ }^{6}$

${ }^{I}$ Research Scholar, Shalom Institute of Health and Allied Sciences, Sam Higginbottom University of Agriculture, Technology and Sciences (SHUATS), Allahabad, India

${ }^{2}$ Assistant Professor, Shalom Institute of Health and Allied Sciences, Sam Higginbottom University of Agriculture, Technology and Sciences (SHUATS), Allahabad, India

${ }^{3}$ Professor, Faculty of Health Sciences, Pokhara University, Pokhara Lekhnath, Kaski, Nepal

${ }^{4}$ Assistant Professor, Department of Mathematics \& Statistics, Sam Higginbottom University of Agriculture, Technology and Sciences (SHUATS), Allahabad, India

${ }^{5}$ Professor and Dean, Shalom Institute of Health and Allied Sciences, Sam Higginbottom University of Agriculture, Technology and Sciences (SHUATS), Allahabad, India

${ }^{6}$ Teaching Associate, Shalom Institute of Health and Allied Sciences, Sam Higginbottom University of Agriculture, Technology and Sciences (SHUATS), Allahabad, India

Antenatal Care (ANC) is an essential component of maternal health service and every woman should receive at least four ANC as prescribed. The aim of this study was to determine the individual, household and community factors responsible for the utilization of the $A N C$.

\section{METHODS}

An analytical cross-sectional study was conducted in the three randomly selected districts representing the three ecological zones of Nepal among 1302 women with a face to face interview.

\section{RESULTS}

The result of the study showed that $60.8 \%$ women received at least 4 ANC according to a national guideline. In multivariate analysis based on the binary logistic regression analysis six out of twelve individual (education (secondary and higher), occupation (business), media exposure, knowledge on BP\&CR, knowledge on 4 ANC and knowledge on 4 ANC incentive), five-out of-eight household (family size ( $\leq 4)$, ethnicity (Brahmin/Chhetri), source of household income (job and remit), household income (middle, fourth and highest), sex of decision maker in household regarding health care (female)) and six out of ten community (involvement in community organization, involvement in income saving in community, access to $\mathrm{FCHV}$, distance to nearest government health facility $(\leq 2 \mathrm{~km})$, availability of public transportation and time taken to reach nearest government health facility ( $\leq 30$ minutes)) factors were revealed as important determinants for the utilization of ANC.
} 


\section{CONCLUSIONS}

It is concluded that several individual, household and community factors have a significant role in the utilization of the ANC. It is recommended to raise the women's status in the family and community through higher education and empowerment. Awareness on ANC through mass media and community volunteers is also crucial. Greater attention should be provided by public authorities to make ANC accessible and available to all women, especially ethnic minorities, disadvantaged and women with low socioeconomic status.

KEYWORDS: Antenatal Care, Determinants, Nepal, Multivariate Analysis \& Binary Logistic Regression Analysis

Received: Jul 28, 2018; Accepted: Aug 18, 2018; Published: Sep 04, 2018; Paper Id.: IJMPSOCT20182

\section{INTRODUCTION}

Globally, every day about 830 women die from preventable causes related to pregnancy and child birth (1). About 99\% of these deaths occur in the developing countries with almost two-third in Sub-Saharan Africa and one-third in Southern Asia (2). It is estimated that the global maternal mortality ratio is 216 per 100000 live births with 239 per 100 000 live births in the developing countries and only 12 per 100000 live births in the developed countries (3).

Most of these maternal deaths are preventable with access to and the utilization of quality maternal health services during pregnancy, child birth and postpartum (1). The ICPD 1994 states that maternal health can be promoted by "education and services for antenatal care, safe delivery, and post-natal care, prevention of abortion, management of unsafe abortion and safe abortion services, referral for diagnosis and treatment for the complication of pregnancy, delivery and abortion" $(4,5)$.

Antenatal care indicates the care of women during pregnancy, which includes a number of services including educating women on healthy pregnancy behaviors, danger signs of complications, neonatal care, breastfeeding and family planning, screening, management and refer (if required) for pregnancy related problems and complications, providing essential care, supplements and prophylactics and encouraging the women to deliver in a health facility with a skilled birth attendant. At least four antenatal visits are recommended for all the pregnant women; first at 4 , second at 6 , third at 8 and fourth at 9 months of pregnancy (6-8).

The recent data showed that only six out of ten (60\%) women received at least four ANC service in Nepal (9). Still now there is a low availability and access to quality maternal health services, especially in developing countries and in remote villages. The utilization of the available maternal health services is also very low due to several demographic, socioeconomic and other factors that present at the individual, household and community level $(1,10,11)$. The objective of this study was to determine the role of the individual, household and community factors for the utilization of Antenatal Care (ANC) in Nepal.

\section{METHOD}

An analytical cross sectional study was conducted in the three randomly selected districts representing three ecological zones of Nepal. Jumla, Myagdi and Kanchanpur districts were randomly selected from the Mountain, Hill and Terai respectively. The sample size was obtained separately for each district initially and added to obtain the entire sample size. A total number of 1302 (430, 427 and 445 from Jumla, Myagdi and Kanchanpur) sample size was obtained with the known prevalence $(51.1 \%, 47.8 \%$ and $56.8 \%$ in Jumla, Myagdi and Kanchanpur) at $95 \%$ confidence interval with the 
known sample population (5320, 4490 and 22215 in Jumla, Myagdi and Kanchanpur) with design effect 1.2 using formula $\mathrm{n}=\left[\mathrm{z}^{2} \mathrm{pqN} / \mathrm{d}^{2}(\mathrm{~N}-1)+\mathrm{z}^{2} \mathrm{pq}\right] \mathrm{DEEF}$.

Women of 15-49 years, who gave birth in two years preceding data collection and had a living child of 0-23 months were selected as the study population. Multi stage sampling was adopted in this study. In the first step, one district from each ecological zone was selected, based on the stratified random sampling. In the second step, each selected district was divided into several strata based on the local administrative units (village development committee and municipality) and 10 local administrative units were selected randomly, again based on stratified random sampling. In the third step, 3 clusters from each local administrative units were selected randomly. Hence there were 90 clusters (30 from each district) selected for the study. In the fourth step, the required number of the samples from each cluster was determined proportionately based on the total number of eligible samples in the cluster. In the fifth step, the respondents to be interviewed from each cluster were determined by systematic random sampling.

Data were collected by six well trained enumerators (two enumerators in each district) between FebruarySeptember 2017 using pretested semi structured interview schedule with a face to face interview. Initially English version of the tool was prepared and then translated into Nepali. Again, it was translated to English to ensure that the meanings of the questions were not changed. The tool consisted four parts: individual factors, household factors, community factors and utilization of Antenatal Care. Utilization of Antenatal Care was the outcome variable. If a woman receives at least four Antenatal care first at 4 , second at 6 , third at 8 and fourth at 9 months of pregnancy, then it was operationally defined as the effective utilization of Antenatal Care. There were 12 individual, 8 household and 10 community level independent variables.

All the filled in questionnaires were crossed checked for completeness and consistency and verified at the evening on the same day of data collection. Data entry was carried out in Epi Data 3.1 software. All the data were inserted in the SPSS 22 version for analysis. Univariate analysis was carried out to describe the utilization of Antenatal Care. Pearson's chi-square test was applied for bivariate analysis. The binary logistic regression analysis was used for multivariate analysis. Both unadjusted and adjusted odd ration was obtained with $95 \%$ confidence interval for final interpretation.

Ethical approval was obtained from the Institutional Review Committee, Pokhara University Research Center, Nepal on $13^{\text {th }}$ February 2017 (Ref. no. 107/073/074) and from the Institutional Ethical Committee for Biomedical Research on Human Participants, Sam Higginbottom University of Agriculture, Technology and Sciences on $21^{\text {st }}$ March 2017 (Reg. no. IEC/SHUATS/2017/B/54). The objectives of the study, benefits and possible harms for the respondents were explained and informed consent were obtained before conducting the interview. The study was carried out with the full compliance of ethical guideline for conducting the research on human participant.

\section{RESULTS}

Only 1276 samples were included for the final analysis and interpretation, since $26(2 \%)$ samples were with important data missing. Information regarding the utilization of Antenatal Care (ANC) is presented in the Table 1. The findings of the study revealed that nine out of ten women (92.0\%) received ANC during last pregnancy. About seven out of ten women (68.9\%) received at least four times ANC. But, only six out of ten women (60.8\%) received at least four ANC according to the national guideline i. e. first at 4 month, second at 6 month, third at 8 month and fourth at 9 month. 
Table 1: Information regarding the utilization of Antenatal Care $(n=1276)$

\begin{tabular}{|c|c|c|}
\hline Variables & Frequency & Percentage \\
\hline \multicolumn{3}{|c|}{ ANC during Last Pregnancy } \\
\hline \begin{tabular}{l|l} 
Yes & \\
\end{tabular} & 1174 & 92.0 \\
\hline No & 102 & 8.0 \\
\hline \multicolumn{3}{|c|}{ Frequency of Antenatal Care } \\
\hline$\leq 4$ visits & 397 & 31.1 \\
\hline$\geq 4$ visits & 879 & 68.9 \\
\hline \multicolumn{3}{|c|}{ Timing of Antenatal Care* } \\
\hline 4 month & 951 & 74.5 \\
\hline 6 month & 964 & 75.5 \\
\hline 8 month & 996 & 71.1 \\
\hline \begin{tabular}{|c|}
9 month \\
\end{tabular} & 1099 & 86.1 \\
\hline $\begin{array}{l}\text { All } 4 \text { ANC according to } \\
\text { Guideline }\end{array}$ & 776 & 60.8 \\
\hline
\end{tabular}

The association between individual factors and the utilization of Antenatal Care are presented in the Table 2. Based on the bivariate analysis using Pearson's chi squire $\left(\chi^{2}\right)$ test, ten out of 12 individual factors were significantly associated with the utilization of Antenatal Care $(\mathrm{P}<0.05)$.

However, in the multiple logistic regression analysis, education of woman (secondary and higher), occupation of woman (business), frequency of media exposure, knowledge on at least three components of BP\&CR, knowledge on 4 ANC according to national guideline and knowledge on 4 ANC incentive were revealed as determinants for the utilization of Antenatal Care.

The association between household factors and the utilization of Antenatal Care are presented 3. Bivariate analysis based on Pearson's chi square test revealed that four out of eight household factors were statistically significantly associated with the utilization of Antenatal Care $(\mathrm{P}<0.05)$.

Table 2: The Association between Individual Factors and the Utilization of Antenatal Care

\begin{tabular}{|c|c|c|c|c|c|c|c|}
\hline \multirow[t]{2}{*}{ Independent Variables } & \multicolumn{2}{|c|}{$\begin{array}{c}4 \text { ANC Visits According to } \\
\text { National Guideline }\end{array}$} & \multirow{2}{*}{\begin{tabular}{|c} 
Bivariate \\
Analysis \\
P value \\
\end{tabular}} & \multicolumn{4}{|c|}{ Multivariate Logistic Regression Analysis } \\
\hline & Yes $(60.8 \%)$ & No $(39.2 \%)$ & & UOR & $95 \% \mathrm{CI}$ & AOR & $95 \% \mathrm{CI}$ \\
\hline \multicolumn{8}{|c|}{ Age of Woman } \\
\hline $15-19$ & $83(62.9)$ & $49(37.1)$ & $<.001 *$ & 3.989 & $2.304-6.906$ & 1.152 & $.499-2.656$ \\
\hline $20-34$ & $662(63.7)$ & $378(36.3)$ & & 4.124 & $2.659-6.396$ & 1.196 & $.622-2.300$ \\
\hline$\geq 35$ & $31(29.8)$ & $73(70.2)$ & & 1.000 & & 1.000 & \\
\hline \multicolumn{8}{|c|}{ No. Living of Children } \\
\hline 1 & $376(70.4)$ & $158(29.6)$ & $<.001 *$ & 8.065 & 4.618-14.085 & 2.623 & $.544-12.637$ \\
\hline $2-3$ & $382(57.6)$ & $281(42.4)$ & & 4.607 & $2.664-7.968$ & 1.355 & $.621-2.956$ \\
\hline$\geq 4$ & $18(22.8)$ & $61(77.2)$ & & 1.000 & & 1.000 & \\
\hline \multicolumn{8}{|c|}{ Birth Order of Last Child } \\
\hline 1 & $369(70.7)$ & $153(29.3)$ & $<.001 *$ & 3.290 & $2.449-4.420$ & .686 & $.163-2.883$ \\
\hline 2 & $278(61.9)$ & $171(38.1)$ & & 2.218 & $1.649-2.983$ & 1.178 & $.753-1.842$ \\
\hline$\geq 3$ & $129(42.3)$ & $176(57.7)$ & & 1.000 & & 1.000 & \\
\hline \multicolumn{8}{|c|}{ Sex of Last Child } \\
\hline Female & $340(63.0)$ & $200(37.0)$ & .178 & 1.000 & & 1.000 & \\
\hline Male & $436(59.2)$ & $300(40.8)$ & & .855 & $.680-1.074$ & 1.058 & $.777-1.441$ \\
\hline \multicolumn{8}{|c|}{ Age of Last Child } \\
\hline $0-11$ & $431(59.8)$ & $290(40.2)$ & .387 & .905 & $.721-1.135$ & .965 & $.703-1.324$ \\
\hline $12-23$ & $345(62.2)$ & $210(37.8)$ & & 1.000 & & 1.000 & \\
\hline
\end{tabular}




\begin{tabular}{|c|c|c|c|c|c|c|c|}
\hline \multicolumn{8}{|c|}{ Table 2: Contd., } \\
\hline \multicolumn{8}{|c|}{ Education } \\
\hline No education & $106(31.1)$ & $235(68.9)$ & $<.001^{*}$ & 1.000 & & 1.000 & \\
\hline Primary & $174(56.1)$ & $136(43.9)$ & & 2.836 & $2.058-3.909$ & 1.324 & $.869-2.020$ \\
\hline Secondary & $282(74.4)$ & $97(25.6)$ & & 6.445 & $4.656-8.923$ & 1.578 & $1.008-2.471$ \\
\hline Higher & $214(87.0)$ & $32(13.0)$ & & 14.826 & $9.581-22.941$ & 2.407 & $1.344-4.311$ \\
\hline \multicolumn{8}{|c|}{ Occupation } \\
\hline House worker & $434(60.6)$ & $282(39.4)$ & $<.001^{*}$ & 1.000 & & 1.000 & \\
\hline Agriculture & $139(51.7)$ & $130(48.3)$ & & .695 & $.524-.921$ & 1.106 & $.754-1.623$ \\
\hline Business & $74(93.7)$ & $5(6.3)$ & & 9.617 & $3.840-24.082$ & 3.348 & $1.119-10.020$ \\
\hline Job & $109(80.1)$ & $27(19.9)$ & & 2.623 & $1.677-4.102$ & 1.450 & $.831-2.529$ \\
\hline Labour\& others & $20(26.3)$ & $56(73.7)$ & & .232 & $.136-.395$ & .595 & $.274-1.292$ \\
\hline \multicolumn{8}{|c|}{ Frequency of Media Exposure } \\
\hline Daily & $131(89.1)$ & $16(10.9)$ & $<.001^{*}$ & 44.659 & $22.401-89.034$ & 7.010 & $3.011-16.322$ \\
\hline Usually & $252(80.3)$ & $62(19.7)$ & & 22.170 & $13.014-37.769$ & 4.183 & $2.115-8.273$ \\
\hline Occasionally & $283(66.6)$ & $142(33.4)$ & & 10.871 & $6.612-17.873$ & 3.580 & $1.920-6.674$ \\
\hline Rarely & $88(35.5)$ & $160(64.5)$ & & 3.000 & $1.777-5.065$ & 2.135 & $1.123-4.061$ \\
\hline Never & $22(15.5)$ & $120(84.5)$ & & 1.000 & & 1.000 & \\
\hline \multicolumn{8}{|c|}{ Knowledge on at Least 3 Danger Signs of Pregnancy } \\
\hline No & $294(44.5)$ & $366(55.5)$ & $<.001 *$ & 1.000 & & 1.000 & \\
\hline Yes & $472(77.9)$ & $134(22.1)$ & & 4.385 & $3.430-5.606$ & 1.024 & $.725-1.446$ \\
\hline \multicolumn{8}{|c|}{ Knowledge on at Least 3 Components of BP\&CR } \\
\hline No & $190(36.4)$ & $332(63.6)$ & $<.001^{*}$ & 1.000 & & 1.000 & \\
\hline Yes & $586(77.7)$ & $168(22.3)$ & & 6.095 & $4.759-7.806$ & 1.543 & $1.093-2.179$ \\
\hline \multicolumn{8}{|c|}{ Knowledge on $4 \mathrm{ANC}$ a/c to National Guideline } \\
\hline No & $163(31.2)$ & $359(68.8)$ & $<.001^{*}$ & 1.000 & & 1.000 & \\
\hline Yes & $613(81.3)$ & $141(18.7)$ & & 9.575 & $7.380-12.423$ & 3.643 & $2.633-5.041$ \\
\hline \multicolumn{8}{|c|}{ Knowledge on 4 ANC Incentive } \\
\hline Yes & $590(84.2)$ & $111(15.8)$ & $.001 *$ & 11.116 & $8.506-14.528$ & 4.232 & $3.058-5.855$ \\
\hline No & $186(32.3)$ & $389(67.7)$ & & 1.000 & & 1.000 & \\
\hline
\end{tabular}

*P is significant at the level of 0.05 . Figures in parenthesis indicate the percentage.

In the multiple logistic regression analysis, family size $(\leq 4)$, ethnicity (Brahmin/Chhetri), source of household income (Job and Remit), household income (middle, fourth and highest) and sex of household decision maker in family regarding health care, were obtained as the significant determinants for the Antenatal Care.

The association between community factors and the utilization of Antenatal Care are presented in the Table 4 . Almost all the community factors were statistically associated with the utilization of Antenatal Care in bivariate analysis based on Pearson's chi square test $(\mathrm{P}<0.05)$.

However, in the multiple logistic regression analysis, six out of ten community factors (involvement in the community organization, involvement in income, saving in the community, access to FCHV, distance to the nearest government health facility, mode of travel (public vehicle) and time taken to reach the nearest government health facility) were established as determinants for the utilization of Antenatal Care. 
Table 3: The Association between Household Factors and the Utilization of Antenatal Care

\begin{tabular}{|c|c|c|c|c|c|c|c|}
\hline \multirow{2}{*}{$\begin{array}{c}\text { Independent } \\
\text { Variables }\end{array}$} & \multicolumn{2}{|c|}{$\begin{array}{l}4 \text { ANC Visit According to } \\
\text { National Guideline }\end{array}$} & \multirow{2}{*}{$\begin{array}{c}\text { Bivariate } \\
\text { Analysis } \\
\text { P Value } \\
\end{array}$} & \multicolumn{4}{|c|}{ Multivariate Logistic Regression Analysis } \\
\hline & Yes $(60.8 \%)$ & No $(39.2 \%)$ & & UOR & $95 \% \mathrm{CI}$ & AOR & $95 \% \mathrm{CI}$ \\
\hline \multicolumn{8}{|c|}{ Family Type } \\
\hline Nuclear & $276(60.4)$ & $181(39.6)$ & .818 & 0.973 & $0.770-1.230$ & 0.682 & $0.455-1.023$ \\
\hline Joint/Extended & $500(61.1)$ & $319(38.9)$ & & 1.000 & & 1.000 & \\
\hline \multicolumn{8}{|c|}{ Family Size } \\
\hline$\leq 4$ & $240(64.9)$ & $130(35.1)$ & .149 & 1.340 & $0.965-1.862$ & 1.774 & $1.058-2.974$ \\
\hline $5-8$ & $390(59.6)$ & $264(40.4)$ & & 1.073 & $0.799-1.440$ & 1.204 & $0.720-1.536$ \\
\hline$>8$ & $146(57.9)$ & $106(42.1)$ & & 1.000 & & 1.000 & \\
\hline \multicolumn{8}{|c|}{ Ethnicity } \\
\hline Dalit & $133(45.9)$ & $157(54.1)$ & $<.001 *$ & 1.000 & & 1.000 & \\
\hline Adibasi/Janjati & $210(55.0)$ & $172(45.0)$ & & 1.441 & $1.061-1.958$ & 0.913 & $0.640-1.301$ \\
\hline Brahmin/Chhetri & $433(71.7)$ & $171(28.3)$ & & 2.989 & $2.234-3.999$ & 1.952 & $1.402-2.716$ \\
\hline \multicolumn{8}{|c|}{ Religion } \\
\hline Hinduism & $662(60.5)$ & $432(39.5)$ & .587 & 1.000 & & 1.000 & \\
\hline Non-Hinduism & $114(62.6)$ & $68(37.4)$ & & 1.094 & $0.791-1.512$ & 1.425 & $0.969-2.096$ \\
\hline \multicolumn{8}{|c|}{ Household Head } \\
\hline Male & $657(61.6)$ & $410(38.4)$ & .209 & 1.000 & & 1.000 & \\
\hline Female & $119(56.9)$ & $90(43.1)$ & & 1.212 & $0.898-1.636$ & 0.721 & $0.514-1.013$ \\
\hline \multicolumn{8}{|c|}{ Income Source } \\
\hline Agriculture & $328(53.7)$ & $283(46.3)$ & $<.001 *$ & 1.000 & & 1.000 & \\
\hline Own business & $117(66.5)$ & $59(33.5)$ & & 1.711 & $1.204-2.431$ & 1.287 & $0.871-1.903$ \\
\hline Job & $140(80.5)$ & $34(19.5)$ & & 3.573 & $2.365-5.338$ & 2.130 & $1.349-3.362$ \\
\hline Remit & $135(79.9)$ & $34(20.1)$ & & 3.426 & $2.277-5.153$ & 1.626 & $1.018-2.599$ \\
\hline Labour\& other & $56(38.4)$ & $90(61.6)$ & & 537 & $0.371-0.777$ & 0.753 & $0.501-1.131$ \\
\hline \multicolumn{8}{|c|}{ Household Income } \\
\hline Lowest & $151(41.8)$ & $210(58.2)$ & $<.001 *$ & 1.000 & & 1.000 & \\
\hline Second & $116(50.2)$ & $115(49.8)$ & & 1.403 & $1.006-1.955$ & 1.114 & $0.780-1.592$ \\
\hline Middle & $142(62.0)$ & $87(38.0)$ & & 2.270 & $1617-3186$ & 1.540 & $1.059-2.239$ \\
\hline Fourth & $189(75.9)$ & $60(24.1)$ & & 4.381 & $3.063-6.267$ & 2.573 & $1.729-3.838$ \\
\hline Highest & $178(86.4)$ & $28(13.6)$ & & 8.841 & $5.637-13.866$ & 5.474 & $3.285-9.115$ \\
\hline \multicolumn{8}{|c|}{ Decision Maker } \\
\hline Male & $256(51.8)$ & $238(48.2)$ & $<.001 *$ & 1.000 & & 1.000 & \\
\hline Female & $520(66.5)$ & $262(33.5)$ & & 1.845 & $1.465-3.224$ & 1.650 & $1.268-2.148$ \\
\hline
\end{tabular}

$* \mathrm{P}$ is significant at the level of 0.05 . Figures in parenthesis indicate the percentage.

\section{DISCUSSIONS}

This study revealed that $92.0 \%$ women received at least one ANC during the last pregnancy. Finding of this study is the consistent with a study conducted in 2013 in the three districts (Bajhang, Dailakh and Kanchanpur) representing the three ecological zones $(88.3 \%)$ and recent demographic health survey of Nepal $(91.1 \%)(12,13)$.

Consistent with the other studies, this study found that $68.9 \%$ women received at least four times ANC (13-15). Similarly, 60.8\% women received at least four ANC with national guidelines in the present study. NDHS, 2016 reported $58.8 \%$ women received least four ANC with national guideline (13). 
Table 4: The Association between Community Factors and the Utilization of Antenatal Care

\begin{tabular}{|c|c|c|c|c|c|c|c|}
\hline \multirow{2}{*}{$\begin{array}{c}\text { Independent } \\
\text { Variables }\end{array}$} & \multicolumn{2}{|c|}{$\begin{array}{l}4 \text { ANC Visit According to } \\
\text { National Guideline }\end{array}$} & \multirow{2}{*}{$\begin{array}{c}\begin{array}{c}\text { Bivariate } \\
\text { Analysis }\end{array} \\
\text { P value } \\
\end{array}$} & \multicolumn{4}{|c|}{ Multivariate Logistic Regression Analysis } \\
\hline & Yes $(60.8 \%)$ & No $(39.2 \%)$ & & UOR & $95 \% \mathrm{CI}$ & AOR & $95 \% \mathrm{CI}$ \\
\hline \multicolumn{8}{|c|}{ Place of Residence } \\
\hline Rural & $393(56.2)$ & $306(43.8)$ & $.001^{*}$ & 1.000 & & 1.000 & \\
\hline Urban & $383(66.4)$ & $194(33.6)$ & & 1.537 & $1.223-1.932$ & .841 & $.495-1.428$ \\
\hline \multicolumn{8}{|c|}{ Ecology of Residence } \\
\hline Mountain & $226(53.2)$ & $199(46.8)$ & $.001^{*}$ & 1.000 & & 1.000 & \\
\hline Hill & $270(64.0)$ & $152(36.0)$ & & 1.564 & $1.188-2.060$ & 1.348 & $.978-1.859$ \\
\hline Terai & $280(65.3)$ & $149(34.7)$ & & 1.655 & $1.256-2.179$ & .885 & $.525-1.493$ \\
\hline \multicolumn{8}{|c|}{ Involvement in Community Organization } \\
\hline Yes & $252(78.0)$ & $71(22.0)$ & $<.001 *$ & 2.906 & $2.169-3.894$ & 2.084 & $1.502-2.891$ \\
\hline No & $524(55.0)$ & $429(45.0)$ & & 1.000 & & 1.000 & \\
\hline \multicolumn{8}{|c|}{ Involvement in Income Saving Groups } \\
\hline Yes & $409(75.9)$ & $130(24.1)$ & $<.001 *$ & 3.172 & $2.484-4.051$ & 1.924 & $1.440-2.571$ \\
\hline No & $367(49.8)$ & $370(50.2)$ & & 1.000 & & 1.000 & \\
\hline \multicolumn{8}{|c|}{ Access to FCHV Service in Community } \\
\hline Yes & $669(69.3)$ & $296(30.7)$ & $<.001 *$ & 4.309 & $3.286-5.650$ & 2.070 & $1.516-2.828$ \\
\hline No & $107(34.4)$ & $204(65.6)$ & & 1.000 & & 1.000 & \\
\hline \multicolumn{8}{|c|}{ Access to Ambulance in Community } \\
\hline Yes & $307(68.8)$ & $139(31.2)$ & $.001 *$ & 1.700 & $1.333-2.167$ & .888 & $.567-1.392$ \\
\hline No & $469(56.5)$ & $361(43.5)$ & & 1.000 & & 1.000 & \\
\hline \multicolumn{8}{|c|}{ Nearest Government Health Facility from Community } \\
\hline UHP & $318(56.1)$ & $249(43.9)$ & $.014 *$ & 1.000 & & 1.000 & \\
\hline IHP & $167(60.7)$ & $108(39.3)$ & & 1.211 & $.903-1.624$ & 1.001 & $.706-1.417$ \\
\hline PHCC & $135(66.5)$ & $68(33.5)$ & & 1.555 & $1.112-2.174$ & .902 & $.581-1.400$ \\
\hline Hospital & $146(67.6)$ & $70(32.4)$ & & 1.633 & $1.174-2.271$ & .911 & $.500-1.662$ \\
\hline Others & $10(66.7)$ & $5(33.3)$ & & 1.566 & $.529-4.640$ & 1.295 & $.389-4.310$ \\
\hline \multicolumn{8}{|c|}{ Distance to Nearest Government Health Facility } \\
\hline$\leq 2 \mathrm{KM}$ & $519(75.9)$ & $165(24.1)$ & $<.001 *$ & 4.100 & $3.229-5.207$ & 2.004 & $1.303-3.083$ \\
\hline$>2 \mathrm{KM}$ & $257(43.4)$ & $335(56.6)$ & & 1.000 & & 1.000 & \\
\hline \multicolumn{8}{|c|}{ Mode of Travel to Nearest Government Health Facility } \\
\hline Walk & $485(54.7)$ & $402(45.3)$ & $<.001 *$ & 1.000 & & 1.000 & \\
\hline Public vehicle & $125(81.2)$ & $29(18.8)$ & & 3.573 & $2.336-5.465$ & 2.688 & $1.621-4.459$ \\
\hline Private vehicle & $166(70.6)$ & $69(29.4)$ & & 1.994 & $1.462-2.720$ & 1.429 & $.895-2.281$ \\
\hline \multicolumn{8}{|c|}{ Time Taken to Reach Nearest Government Health Facility } \\
\hline$\leq 30$ minutes & $546(75.4)$ & $178(24.6)$ & $<.001 *$ & 1.000 & & 1.000 & \\
\hline$>30$ minutes & $230(41.7)$ & $322(58.3)$ & & 4.294 & $3.381-5.455$ & 1.636 & $1.032-2.595$ \\
\hline
\end{tabular}

$* \mathrm{P}$ is significant at the level of 0.05 . Figures in parenthesis indicate the percentage.

Women with secondary (AOR 1.578, 95\% CI: 1.008-2.471) and higher education (AOR 2.407, 95\% CI: 1.3444.311) were more likely to utilize the ANC in this study. In a similar study conducted in Nepal in 2014 also reported the highest level of education significantly associated with both $\geq 4$ ANC and quality ANC (16). Several studies have highlighted that education had the significant role for the utilization of Antenatal Care $(14,17,18)$.

This study revealed that women with business, occupation were about three times (AOR 3.348, 95\% CI: 1.11910.020) more likely to utilize the ANC compared to the house worker. Similar findings were reported in studies from two developing countries, India and Cambodia $(19,20)$. It is well known that women who are involved in an occupation with regular cash income are more likely to utilize the health services. 
The present study revealed that women's greater media exposure as an important determinant for the utilization of the ANC, which is similar to a study conducted in Kenya (21). In addition, studies from Nepal also reported the positive influence of mass media for the utilization of $\mathrm{ANC}(16,22)$.

This study reported that women's knowledge on BP\&CR significantly affect (AOR 1.543, 95\% CI: 1.093-2.179) the utilization of the ANC. Evidences supported that BP\&CR is an effective intervention for raising the utilization of maternal health care services in Nepal too $(15,23,24)$.

This study also showed that knowledge on 4 ANC, according to national guideline was statistically associated (AOR 3.643, 95\% CI: 2.633-5.041) with the utilization of the ANC. The studies from Myanmar and Ethiopia also suggested the knowledge and awareness of the maternal health services as an important predictor for the utilization of maternal health services $(25,26)$.

Our study showed a strong statistical association between knowledge on 4 ANC incentive (AOR 4.232, (95\% CI: 3.058-5.855) and the utilization of Antenatal Care in the multivariate analysis. Studies from Nepal and aboard also concluded the positive impact of cash incentive for the utilization of maternal health services (27-30).

The result of the current study revealed that women from family size $\leq 4$ was about two times (AOR $1.774,95 \%$ CI: 1.058-2.974) more likely to utilize the ANC than women with family size $\geq 8$. Consistent with a study from India also concluded that the utilization of maternal health services were higher in smaller families compared with large family size (31).

Likewise, present study concluded that women from Brahmin/Chhetri were about two times (AOR 1.952, 95\% CI: 1.402-2.716) more likely to utilize ANC than women disadvantaged Dalit ethnic group. The results of the recent studies from Nepal also concluded that women from ethnic minorities and disadvantaged groups were less likely to utilize maternal health services $(15,32)$. It may be that women with a higher ethnic group are more educated and have more access to health services.

This study showed the statistical association between household income (middle, fourth and highest) and the utilization of Antenatal Care. The higher the household income, higher the utilization of Antenatal Care service, reported by other studies too (33-35).

The present study concluded that sex of decision maker regarding health care (female) in the household also influence in receiving Antenatal Care. Evidences suggested that the utilization of Antenatal Care is more common among the women who have autonomy in decision making $(16,36,37)$. However, no studies have been found that evaluated the differences in the utilization of Antenatal Care between male and female decision maker regarding health care in a household. This indicates females can understand health condition and health need of the females better than the male.

The present study showed that women involved in various community organizations (AOR 2.084, 95\% CI: 1.5022.891) and income saving in the community level (AOR 1.924, 95\% CI: 1.440-2.571) were more likely to utilize Antenatal Care. In support to this result, a study conducted in India, reported that social networks of women operating at the community level were positively associated with all the antenatal, delivery and postnatal care utilization (38).

Likewise, the present study reported that women who were living in the communities with an access to the female community health volunteer were two times (AOR: $2.070,95 \% \mathrm{CI}$ : 1.516-2.828) more likely to utilize ANC than those 
women living in the communities with no access to the female community volunteer. The role of women's health volunteer groups for the diffusion of maternal health knowledge and thereby utilization of maternal health services has established by many studies in Nepal and as well as in aboard (30, 39-41).

Distance to the nearest health facility is positively associated with ANC in this study as like other studies $(42,43)$. This study found that women who were living in the communities with the distance to the nearest government health facility $\leq 2$ kilometer were two times (AOR 2.004, 95\% CI: 1.303-3.083) more likely to receive ANC compared to women living in the communities with distance to the nearest government health facility $>2$ kilometer. In fact, physical access to the health service is also an important determinant for the utilization of maternal health services including Antenatal Care.

Access to transportation also reported as a significant factor for receiving ANC in the present study. Some systematic reviews and qualitative studies from Nepal reported that there is a low utilization of available maternal health services in rural, mountains and hilly areas due to lack of transportation or poor transportation (44-46).

Similarly, women who had to travel $\leq 30$ minutes to reach the nearest government health facility were about one and a half times (AOR 1.636, 95\% CI: 1.032-2.595) more likely to utilize ANC than those who had to travel >30 minutes. Lesser the time to reach the health facility, higher the utilization of maternal health services, especially delivery care and care for other emergency obstetric complications has been reported by many studies $(46,47)$.

\section{CONCLUSIONS}

The study concluded that several individual, household and community factors have a significant role in utilization of antenatal care. It is recommended to provide higher education for girls and aware women on antenatal care using various mass media to address individual factors. Similarly, it is essential to raise the status of women in the family and community with special emphasis on women from ethnic minorities and disadvantaged groups. Attentions should also be provided by public authorizes to make maternal health service accesses to all women.

\section{REFERENCES}

1. WHO. Maternal mortality: fact sheet Geneva, Switzerland World Health Organization; 2015 [updated 2016 Nov; cited 2016 Dec 20]. Available from: http://www.who.int/mediacentre/factsheets/fs348/en/.

2. Say L, Pattinson RC, Gülmezoglu AM. WHO systematic review of maternal morbidity and mortality: the prevalence of severe acute maternal morbidity (near miss). Reproductive Health. 2004;1(1):3.

3. WHO. 10 facts on maternal health 2015 [updated 2015 November; cited 2016 July 15]. Available from: http://www.who.int/features/factfiles/maternal_health/maternal_health_facts/en/.

4. Starrs A, editor. The Safe Motherhood Action Agenda: Priorities for the Next Decade. New York: Family Care International; 1998.

5. UNFPA. Programme of Action. Adopted at the international conference population and development, Cairo, 5-13 september, 1994. 2004.

6. DoHS. Annual Report: Department of Health Services 2072/73 (2015/16). Kathmandu, Nepal: Department of Health Services, Ministry of Health and Population, Government of Nepal; 2017.

7. WHO. Standards for improving quality of maternal and newborn care in health facilities. Geneva, Switzerland: World Health Organization; 2016. 
8. WHO. WHO recommendations on maternal health: guidelines approved by the WHO Guidelines Review Committee. Geneva: World Health Organization; 2017.

9. CBS. Nepal Multiple Indicator Cluster Survey 2014, Final Report. Kathmandu, Nepal: Central Bureau of Statistics, and UNICEF Nepal; 2015. p. 387.

10. WHO. Maternal death review in selected countries of South-East Asia Region. New Delhi, India: World Health Organization, Regional Office for South-East Asia; 2014. 211 p.

11. Shahi P, De Kok B, Tamang PD. Inequity in the Utilization of Maternal-Health Care Services in South Asia: Nepal, India and Sri Lanka. 2016.

12. Choulagai B, Onta S, Subedi N, Mehata S, Bhandari GP, Poudyal A, et al. Barriers to using skilled birth attendants' services in mid- and far-western Nepal: a cross-sectional study. BMC International Health and Human Rights. 2013;13:49.

13. MoH, New ERA, IFC. Nepal Demographic and Health Survey 2016. Kathmandu, Nepal: Ministry of Health, Nepal; 2017.

14. Pradhan P, Bhattarai S, Paudel I, Gaurav K, Pokharel P. Factors contributing to antenatal care and delivery practices in village development committees of Ilam district, Nepal. Kathmandu University Medical Journal. 2014;11(1):60-5.

15. Pathak P, Shrestha S, Devkota R, Thapa B. Factors Associated with the utilization of institutional ielivery service among Mothers. Journal of Nepal Health Research Council. 2017;15(37):228-34.

16. Joshi C, Torvaldsen S, Hodgson R, Hayen A. Factors associated with the use and quality of antenatal care in Nepal: a population-based study using the demographic and health survey data. BMC Pregnancy and Childbirth. 2014;14(1):94.

17. Pandey S, Karki S. Socio-economic and demographic determinants of Antenatal Care Services Utilization in Central Nepal. International journal of MCH and AIDS. 2014;2(2):212-9.

18. Tripathi V, Singh R. Ecological and socio-demographic differences in maternal care services in Nepal. Peer J. 2015;3:e1215.

19. Sridharan S, Dey A, Seth A, Chandurkar D, Singh K, Hay K, et al. Towards an understanding of the multilevel factors associated with maternal health care utilization in Uttar Pradesh, India. Global Health Action. 2017;10(1):1287493.

20. Sagna ML, Sunil T. Effects of individual and neighborhood factors on maternal care in Cambodia. Health \& place. 2012;18(2):415-23.

21. Achia TN, Mageto LE. Individual and contextual determinants of adequate maternal health care services in Kenya. Women \& health. 2015;55(2):203-26.

22. Acharya D, Khanal V, Singh JK, Adhikari M, Gautam S. Impact of mass media on the utilization of antenatal care services among women of rural community in Nepal. BMC Research Notes. 2015;8:345.

23. Acharya P, Adhikari TB, Neupane D, Thapa K, Bhandari PM. Correlates of institutional deliveries among teenage and nonteenage mothers in Nepal. PLoS ONE. 2017;12(10):e0185667.

24. Karkee R, Baral OB, Khanal V, Lee AH. The role of obstetric knowledge in utilization of delivery service in Nepal. Health Education Research. 2014;29(6):1041-8.

25. Chamroonsawasdi K, Soe M, Charupoonphol P, Srisorrachatr S. Rate of utilization of skilled birth attendant and the influencing factors in an urban Myanmar population. Asia Pacific Journal of Public Health. 2015;27(5):521-30.

26. Siemuri, K. E., Oladayo, O. F., \& Ugochukwu, N. C. (2014). Factors influencing the utilization of the nursing process in Ogun State, Nigeria. International Journal of General Medicine and Pharmacy (IJGMP), 3, 57-64. 
27. Worku AG, Yalew AW, Afework MF. Factors affecting utilization of skilled maternal care in Northwest Ethiopia: a multilevel analysis. BMC International Health and Human Rights. 2013;13(1):20.

28. Ensor T, Bhatt H, Tiwari S. Incentivizing universal safe delivery in Nepal: 10 years of experience. Health policy and planning. 2017;32(8):1185-92.

29. Witter $S$, Khadka $S$, Nath H, Tiwari S. The national free delivery policy in Nepal: early evidence of its effects on health facilities. Health policy and planning. 2011;26(suppl 2):ii84-ii91.

30. Subedi S, Kaphle HP, Acharya S, Gupta N, Jain V. Maternal incentive scheme in Nepal-status of knowledge and financial benefits received by mothers on ANC incentive and safe delivery incentive program. Indian Journal of Community Health. 2014;26(3):273-7.

31. Deo KK, Paudel YR, Khatri RB, Bhaskar RK, Paudel R, Mehata S, et al. Barriers to utilization of antenatal care services in Eastern Nepal. Frontiers in Public Health. 2015;3:197.

32. Srivastava A, Mahmood SE, Mishra P, Shrotriya VP. Correlates of Maternal Health Care Utilization in Rohilkhand Region, India. Annals of Medical and Health Sciences Research. 2014;4(3):417-25.

33. Adhikari R. Effect of Women's autonomy on maternal health service utilization in Nepal: a cross sectional study. BMC Women's Health. 2016;16:26.

34. Karkee R, Lee AH, Khanal V. Need factors for utilisation of institutional delivery services in Nepal: an analysis from Nepal Demographic and Health Survey, 2011. BMJ Open. 2014;4(3):e004372.

35. Bhatta DN, Aryal UR. Paternal factors and inequity associated with access to Maternal Health Care Service Utilization in Nepal: A community based cross-sectional study. PLoS One. 2015;10(6):e0130380.

36. Babalola SO. Factors associated with use of maternal health services in Haiti: a multilevel analysis. Rev Panam Salud Publica. 2014;36(1):1-9.

37. Tarekegn SM, Lieberman LS, Giedraitis V. Determinants of maternal health service utilization in Ethiopia: analysis of the 2011 Ethiopian Demographic and Health Survey. BMC Pregnancy Childbirth. 2014;14:161.

38. Mpembeni RN, Killewo JZ, Leshabari MT, Massawe SN, Jahn A, Mushi D, et al. Use pattern of maternal health services and determinants of skilled care during delivery in Southern Tanzania: implications for achievement of MDG-5 targets. BMC Pregnancy and Childbirth. 2007;7(1):29.

39. Story WT. Social capital and the utilization of maternal and child health services in India: A multilevel analysis. Health \& place. 2014;28:73-84.

40. Oguro M, Horiuchi S. A Cross-Sectional Study of Community-Based Maternal and Child Health Interventions involving women's health volunteer groups in rural Myanmar. Public Health Nursing. 2016;33(5):449-59.

41. Singh MK, Singh JV, Ahmad N, Kumari R, Khanna A. Factors Influencing Utilization of ASHA services under NRHM in relation to maternal health in rural Lucknow. Indian Journal of Community Medicine : Official Publication of Indian Association of Preventive \& Social Medicine. 2010;35(3):414-9.

42. New Era. An analytical report on national survey of female community health volunteers of Nepal. USAID, 2008.

43. Tsawe M, Susuman AS. Determinants of access to and use of maternal health care services in the Eastern Cape, South Africa: a quantitative and qualitative investigation. BMC Research Notes. 2014;7:723. 

Arvind Dayal \& Akanksha Singh

44. Birmeta K, Dibaba Y, Woldeyohannes D. Determinants of maternal health care utilization in Holeta town, central Ethiopia. BMC Health Services Research. 2013;13:256-.

45. Simkhada B, Van Teijlingen E, Porter M, Simkhada P. Major problems and key issues in Maternal Health in Nepal. Kathmandu University Medical Journal. 2006;4(2 (Iss):258-63.

46. Shrestha S, Bell JS, Marais D. An analysis of factors linked to the decline in Maternal Mortality in Nepal. PLoS ONE. 2014;9(4):e93029.

47. Karkee R, Lee A, Binns $C$. Why women do not utilize maternity services in Nepal: a literature review. WHO South-East Asia Journal of Public Health. 2013;2(3):135-41.

48. Sharma SR, Poudyal AK, Devkota BM, Singh S. Factors associated with place of delivery in rural Nepal. BMC Public Health. 2014; 14:306. 